\title{
"The effectiveness of the project management application analysis in the Kazakhstani defense industrial complex holding"
}

\begin{tabular}{|c|c|}
\hline \multirow{7}{*}{ AUTHORS } & Alizhan Tulembayev (D) https://orcid.org/0000-0002-4909-076X \\
\hline & R http://www.researcherid.com/rid/G-8742-2019 \\
\hline & Aliya Adilova (D https://orcid.org/0000-0001-9962-7898 \\
\hline & Askhat Serikbekuly (D https://orcid.org/0000-0002-1232-5238 \\
\hline & R http://www.researcherid.com/rid/G-7928-2019 \\
\hline & Dina Seidaliyeva \\
\hline & Yerlan Shildibekov (D) https://orcid.org/0000-0003-3970-6740 \\
\hline ARTICLE INFO & $\begin{array}{l}\text { Alizhan Tulembayev, Aliya Adilova, Askhat Serikbekuly, Dina Seidaliyeva and } \\
\text { Yerlan Shildibekov (2020). The effectiveness of the project management } \\
\text { application analysis in the Kazakhstani defense industrial complex holding. } \\
\text { Problems and Perspectives in Management, 18(3), 141-149. } \\
\text { doi:10.21511/ppm.18(3).2020.12 }\end{array}$ \\
\hline DOI & http://dx.doi.org/10.21511/ppm.18(3).2020.12 \\
\hline RELEASED ON & Thursday, 27 August 2020 \\
\hline RECEIVED ON & Wednesday, 10 June 2020 \\
\hline \multirow[t]{2}{*}{ ACCEPTED ON } & Wednesday, 12 August 2020 \\
\hline & $(\mathrm{cc}) \mathrm{EY}$ \\
\hline LICENSE & $\begin{array}{l}\text { This work is licensed under a Creative Commons Attribution } 4.0 \text { International } \\
\text { License }\end{array}$ \\
\hline JOURNAL & "Problems and Perspectives in Management" \\
\hline ISSN PRINT & $1727-7051$ \\
\hline ISSN ONLINE & $1810-5467$ \\
\hline PUBLISHER & LLC “Consulting Publishing Company "Business Perspectives" \\
\hline FOUNDER & LLC "Consulting Publishing Company "Business Perspectives" \\
\hline
\end{tabular}

NUMBER OF REFERENCES

26
NUMBER OF FIGURES

0

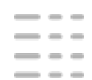

NUMBER OF TABLES

1

(C) The author(s) 2021. This publication is an open access article. 


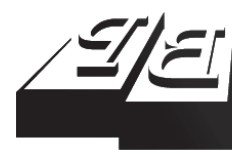

BUSINESS PERSPECTIVES

(2)

LLC "CPC "Business Perspectives"

Hryhorii Skovoroda lane, 10,

Sumy, 40022, Ukraine

www.businessperspectives.org

Received on: $10^{\text {th }}$ of June, 2020

Accepted on: $12^{\text {th }}$ of August, 2020

Published on: 27th of August, 2020

() Alizhan Tulembayev, Aliya Adilova Askhat Serikbekuly, Dina Seidaliyeva, Yerlan Shildibekov, 2020

Alizhan Tulembayev, Ph.D., Head of the Department of Engineering and Innovations, JSC "National company «Kazakhstan Engineering»", NurSultan, Kazakhstan.

Aliya Adilova, Ph.D., Kazakh Ablai Khan University of International Relations and World Languages, Almaty, Kazakhstan. (Corresponding author)

Askhat Serikbekuly, Ph.D., "Intelligent Data Solutions" LLP, Almaty, Kazakhstan.

Dina Seidaliyeva, Doctoral Candidate, G.N. Gumilyov Eurasian National University, Nur-Sultan, Kazakhstan.

Yerlan Shildibekov, Ph.D., International IT University, Almaty, Kazakhstan.
Alizhan Tulembayev (Kazakhstan), Aliya Adilova (Kazakhstan), Askhat Serikbekuly (Kazakhstan), Dina Seidaliyeva (Kazakhstan), Yerlan Shildibekov (Kazakhstan)

\section{THE EFFECTIVENESS OF THE PROJECT MANAGEMENT APPLICATION ANALYSIS IN THE KAZAKHSTANI DEFENSE INDUSTRIAL COMPLEX HOLDING}

\begin{abstract}
Nowadays, leading world companies widely use methodology, standards, and project management tools in many areas of project-oriented activities, including investment, innovation, and information projects. Last years the implementation and functioning of the country's enterprises' project management system have been actively discussed in Kazakhstan.
\end{abstract}

This work aims to identify critical processes of project management planning that af fect the effectiveness of projects at the enterprise of the military-industrial complex of Kazakhstan. For this purpose, a survey of top managers of defense industry companies was conducted. A total of 28 respondents were interviewed, working at 18 enterprises of the military-industrial complex of the Republic of Kazakhstan and directly participating in the implementation of projects. Data were personally collected by a questionnaire survey conducted during 2019. To verify the formulated model's assumptions and success, correlation analysis, and other relevant tests were used. Using the model of project management planning quality (PMPQ), process efficiency has been assessed, and critical factors for the effectiveness of defense industry projects have also been identified. The results show that the Republic of Kazakhstan's defense industry complex projects has a low level of efficiency and an average score for the use of project planning processes. Project efficiency evaluation has also revealed critical knowledge areas for defense projects like human resource management, schedule development, and define scope. The research expands knowledge in PM, revealing the importance of planning processes for the defense industry that need more focus to achieve top-level success and effectiveness of projects.

Keywords project management, project planning, defense, methodology, PMPQ model, project success, project performance

\section{JEL Classification $\quad \mathrm{M} 10, \mathrm{~L} 10, \mathrm{O} 22$}

\section{INTRODUCTION}

Project management is an independent field of knowledge that has been successfully used in enterprise management systems in various industries around the world. Having adopted the standard ST RK ISO 21500-2014 - Project Management Guide as a national standard in project management, Kazakhstan has begun a new stage in the development of management in large private companies and national companies in the quasi-public sector. Since then, the topic of introducing project management tools and methods into the activities of companies in various industries has become quite relevant, but the pace, speed, and scale of this process are low.

The Kazakhstani military-industrial complex is compact with various types of enterprises carrying out almost all types of products and ser- 
vices of weapons and military equipment. In addition to the main special products, almost all enterprises produce civil engineering products.

Despite the high interest of scientists and the availability of research related to projects in the defense industry, there is still a limitation of relevant literature on the analysis of the effectiveness of projects in this field.

The paper investigates the level of effectiveness of military-industrial complex projects and the critical factors affecting project efficiency in terms of project management.

\section{LITERATURE REVIEW}

The countries spend billions of dollars and use a significant amount of resources for large-scale defense systems projects. Many publications indicate that large-scale defense systems are among the most complex and risky projects (Demir, 2017).

Defense projects are usually implemented as part of the project management system, where the general aim of managers is to reach the topmost efficiency of the project. The study of Frinsdorf and Zuo (2014) showed that defense projects' effectiveness goes beyond its traditional internal focus and becomes externally-oriented. As a result, efforts are required not only for those factors that are associated with individual projects but also for those that are related to the interdependence of projects and external customers. Management of defense industry projects by the interested parties will improve the efficiency of projects in this sector of the economy.

Many projects in the defense industry involve developing a new product. Among the many works devoted to the research of the project success factors, the work of Rodríguez-Segura, Ortiz-Marcos, Romero, and Tafur-Segura (2016) should be noted. This work presents the analysis of twenty-nine major sectoral projects in the sphere of defense. After analyzing various criteria and factors influencing the project's success, a conclusion has been made that not all criteria or factors affect the project's ultimate success. The results confirm how important the client, company, and time are for success as a success criterion.

Some scientists claim that "defense projects themselves are complex systems, and traditional approaches have failed because their linear logic inadequately captures the dynamics of complex adaptive systems" (Cantwell, Sarkani, \& Mazzuchi, 2012). Changetal's (2013) research is also dedicated to this direction, stating that "unlike the traditional methodology of product-oriented projects, the prospect of value creation proves the importance of creating new knowledge, processes, and systems for suppliers and customers". In the research, the scientist cites interview data for three Australian defense megaprojects to demonstrate that senior executives have a more sophisticated view of project success than traditional iron triangle indicators.

Although the usefulness of traditional approaches for defense projects is ambiguous, the need for project management is not in doubt. Recently, Paton and Andrew (2019) described a case study in the defense industry and found that PMOs (project management offices) can ensure continuity at all stages while maintaining consistent goals, processes, and methods.

As mentioned earlier (Tulembayev, Jumadilova, Adilova, \& Seidaliyeva, 2019), in Kazakhstan, "active work is currently underway to introduce a project approach to the management of the production processes of new products. However, even if the need to implement project management is undeniable, the question arises in the degree of readiness of defense enterprises for these innovations".

The project's effectiveness as a whole is evaluated to determine the potential attractiveness of the project for its stakeholders. It includes socio-economic and commercial effectiveness (to determine potential attractiveness of the project for its participants and includes socio-economic and commercial effectiveness). One of the largest aspects of improving the project management system is 
evaluating its effectiveness, which allows monitoring and timely adjustments in case of deviations (Baklanova, 2010).

Most project managers are confronted with various factors that influence the success or failure of projects. These factors are called "Critical Success Factors" (CSF) and must be present in order for the project to have a high probability of success. For the first time, Daniel (1961) speaks about CSF. Rubin and Seeling (1967) applied the CSF model for the first time in the field of project management. They investigated the influence of a project manager's experience and the size of previous projects on the success of the current project. They determined the strong influence of the first level of the model, focusing on the product's success, and therefore on the success of the project.

Conducting a large-scale study on CSF, Pinto and Slevin (1987) identified ten key CSFs that greatly impacted project success. Subsequently, many researchers stuck to this line of factors for various types of projects and began to argue that planning is considered in project management as one of the main success factors for a project (Dvir, Raz, \& Shenhar, 2003; Glenn, 2008; Kozhakhmetova, Zhidebekkyzy, Turginbayeva, \& Akhmetova, 2019) Moreover, Dvir et al. (2003) identified a positive relationship between the effort put into project planning and project success, and Glenn (2008) identified the stage of project planning as one of the factors for successful enterprise resource planning.

There are substantiated conclusions about the role of the project management methodology (PMM) as a factor in the success of projects (Junqueira \& Passador, 2019), which should be taken into account when developing a project plan, in our opinion, is a subjective factor.

In addition to developing a project plan, which, in our opinion, is a subjective factor, it is necessary to take into account the methodology of project management.

The methodology, just the same, provides objectivity in all project management processes and thus affects the success of the project (Joslin \& Muller, 2015). The formed conclusions based on 254 re- spondents' responses to the worldwide cross-sectional online survey showed that when applying the PMM, the success of the project is more often achieved by $22.3 \%$. To increase the level of achievement of project success, it is necessary to understand how comprehensive the methodology is at the moment, or it is necessary to constantly update, supplement it during the project. In any case, project management guidance is the foundation, and add-ons are a creative part for the project manager.

At the same time, one more study can be found in the literature, in which planning processes are examined in detail, and the relationship of the quality of planning with the success of the project is found (Zwikael \& Globerson, 2006a, 2006b). Comparing CSF in the scientific literature on project management and sorting success factors by citation frequency, it is concluded that CSF factors are not specific enough to support more effective decision making and not specific enough to indicate critical processes at the project planning stage.

The model has been tested and analyzed on various projects by many scientists. Papke-Shields, Beise, and Quan (2010) expanded the model to include items related to the initiation, implementation, monitoring, and project control stages.

An empirical study by Ress-Caldwell and Pinnington (2013) on the impact of the national culture of Arab and British project managers on project management was also conducted using the PMPQ model.

Kozhakhmetova, Gabdullin, Kunanbayeva, Tazhiyeva, and Kydayberganova (2019) used the PMPQ model to identify critical areas of project management knowledge that affect project performance and project management tools that enhance project performance, and when studying the variety of cultures in the project management styles of three Asian countries - Israel, Japan, and Kazakhstan - and identifying the impact of management styles on project success (Kozhakhmetova et al., 2019).

Zwikael and Globerson (2006a, 2006b) argue that project success must be measured by the effectiveness and efficiency of the project. Efficiency is as- 
sessed by time and cost overruns, and project performance is determined by customer satisfaction and achievement of project goals.

\section{AIMS}

The research aims to determine crucial areas of project management knowledge, which have the biggest impact on the defense industry project's effectiveness.

\section{METHODS}

This paper uses the PMPQ model proposed (Zwikael \& Globerson, 2006a), which is based on the planning processes of PМBOK (2004), the results of which should create products that can be measured (for example, Ganttchart, WBS).

At the time of model creation, the fourth edition of the $\mathrm{PMBOK}$ was in practice, in which 21 planning processes out of 44 processes were identified. At present, the sixth edition of the PMBOK is operating, which defines 24 planning processes out of 49 processes. Changes and additions to the PMBOK did not significantly affect the change in the structure of the model since the processes and product created remain unchanged.

The model has been developed in the process of determining those planning processes for which the success of the project is the most vulnerable (CSP) and defines the processes that have the biggest impact on the success of the project, i.e., four indicators of project success, which act as dependent variables of the model (cost overruns, schedule overruns, technical performance, and customer satisfaction).

The questionnaire was chosen as a measuring tool for research. It was conducted among employees of military-industrial complex organizations, where 28 respondents were interviewed, working at 18 enterprises of the military-industrial complex of the Republic of Kazakhstan (including 20 employees of 11 enterprises of KE) and directly participating in the implementation of projects. Every answer was evaluated on a 5-point Likert scale (Gadermann, 2012). The questionnaire items' in- ternal consistency was analyzed by calculating the Cronbach-Likert alpha (Cronbach, 2004), which was found by the following formula:

$$
\alpha=\frac{\mathrm{N}^{*} \mathrm{r}}{\left(1+\mathrm{r}^{*}(\mathrm{~N}-1)\right)}
$$

where $\mathrm{N}$ - number of tested components, $\mathrm{r}-$ average correlation coefficient between components.

\section{RESEARCH RESULTS}

This section introduces the results of the research. The collection of materials for analyzing the functioning of the project management system at the defense industry enterprises of Kazakhstan, and conducting the interviews with company employees who take a key part in project management processes is described in a previous publication (Tulembaev et al., 2019).

At the time of the research, JSC "Kazakhstan Engineering" formed a portfolio of nine projects at the operational stage and four projects at the investment stage.

All projects have common features. They are hightech, requiring the use of advanced technologies and large financial investments. Moreover, such projects are often implemented by highly specialized experts with in-depth knowledge of the complexity of management.

The PMI Institute proposes implementing a series of activities called "project management processes" to manage the project life cycle. Project management processes are grouped into five groups and distributed across ten areas of knowledge (PMBOK, 2017), resulting in identifying 49 processes necessary for project management, of which 24 are planning processes. Thus, almost $49 \%$ of all processes are planning processes that must be correctly executed by the project manager throughout the project's life cycle.

This article focuses on project planning processes. This made it easier to test the hypothesis that the planning process is critical to project success.

The interview took place in the form of personal meetings, as well as questionnaires. Each of the 
survey participants received a verbal explanation and a written manual describing all the planning processes. The project managers participating in the survey were asked to evaluate the degree of utilization of the 16 planning processes described in PMBOK. They rated it on a Likert scale from 1 to 5 points, where 5 is the best result, and 1 is the worst. Based on the analysis of the data obtained, this research was conducted.

To validate the questionnaire, an analysis of the internal consistency of the described processes with the definition of Cronbach alpha. The Cronbach coefficient determines the internal consistency of the characteristics describing one object and ranges from 0 to 1 . According to calculations in Excel, $\alpha=0.97$, which is higher than or equal to 0.9 . Thus, the studied processes correlate very well.

The data received from project managers on the intensity of use of pla nning processes gives a general idea of the quality of project planning. Besides, data analysis reveals which project managers often carry out areas of project knowledge. This information is presented in Table 1.

Table 1. Relationship between PM processes and project effectiveness

Source: Update by the authors based on Tulembayev et al. (2019).

\begin{tabular}{|c|c|c|}
\hline Process named & $\begin{array}{c}\text { Average score } \\
\text { number }\end{array}$ & $\begin{array}{l}\text { PMPQ } \\
\text { index }\end{array}$ \\
\hline $\begin{array}{l}\text { Develop project management } \\
\text { plan }\end{array}$ & 4.11 & 3.85 \\
\hline Collect requirements & 3.71 & 3.33 \\
\hline Create WBS & 3.69 & 3.11 \\
\hline Define scope & 3.78 & 3.48 \\
\hline Define activities & 3.56 & 3.33 \\
\hline Sequence activities & 3.53 & 3.18 \\
\hline Develop schedule & 2.89 & 2.81 \\
\hline Estimate activity resources & 3.76 & 3.29 \\
\hline Estimate costs & 4.06 & 3.66 \\
\hline Determine budget & 4.17 & 3.88 \\
\hline Plan quality management & 3.56 & 3 \\
\hline $\begin{array}{l}\text { Plan stakeholder } \\
\text { management }\end{array}$ & 3.39 & 3.22 \\
\hline $\begin{array}{l}\text { Plan human resource } \\
\text { management }\end{array}$ & 3.35 & 2.92 \\
\hline Plan communications & 3.00 & 2.66 \\
\hline Plan risk management & 3.44 & 2.92 \\
\hline Plan procurement & 3.33 & 3.29 \\
\hline
\end{tabular}

Average score data indicate the average value of the degree of use of planning processes by pro- ject managers in the field of the defense industry. Table 1 estimates of the use of planning processes are different. This means that managers use project management planning processes in different ways. Using the average frequency of process generation, practical usage ranges from a maximum of 4.17 for "determine budget" to a minimum of 2.89 for "develop schedule". The average score for planning processes on the Likertscale was 3.58 points. Comparing the results of the application of planning processes, schedule development processes are the weakest points at the planning stage.

Traditionally, project success indicators reflect three aspects of the "Iron Triangle", which are very popular among managers worldwide. The iron triangle shows the main limitations in the projects - this is the time, budget (cost), and the amount of work. Changing either side of the triangle will inevitably lead to a change in others. Very often, in projects, one of the parties is considered unchanged under any circumstances and it is very important at the initial stage to determine which of the parties it is. This will allow making rational decisions in adjusting other parties in case of difficulties during the implementation of the project. In the case of projects of the military-industrial complex of Kazakhstan, the least variable (difficult to change) side is the project budgets, since financing is provided from the state budget. Accordingly, during the project's implementation, particular attention should be paid to determining the timing and scope of work on projects.

The next column in Table 1 presents the PQ index's calculations, acting as the average usage of each of the 16 processes. The maximum possible PQ index is 5 . Cluster analysis conducted by Zwikael et al., (2004) identified three areas of knowledge that differ in the quality of influence on the project's success. Thus, the processes of "Integration", "Scope", "Time", and "Human resource" belong to the field of high quality. The average score for this process group should be 4 points. Areas of medium quality include "Cost", "Procurement", "Quality". The rating of this group is 3 points. Low-quality areas that involve "Risk" and "Communications" are rated at about 2.5 points.

The PMPQ data for the defense industry projects in Kazakhstan show that the average score of the 
processes of medium and low-quality influence the success of the project corresponds to the level of Zwikael and Globerson model. Simultaneously, very low scores demonstrate processes that have top quality affecting the project's success. These are processes such as "develop schedule" (2.8 points) and "plan human resource management" (2.9 points).

\section{DISCUSSION}

Many scientific works are devoted to research on the effectiveness of projects. Papke-Shields, Beise, and Quan (2010) conducted a study at the PMI Regional Office of the eastern United States. Comparing the results of the research (Zwikael et al., 2004)) and their results, they found an exact match in the ranking order and the magnitude of the difference in all situations and supported the presumption that the introduction of project management tools help project success grow. Studies by Ress-Caldwell and Pinnington (2013) and Kozhakhmetova et al. (2019) on the impact of national cultures and management styles in various countries have confirmed it Zwikael, Dutt Pathak, Singh,and Ahmed (2014) claim that cost estimates were not different among project managers of different countries and cultures, and the cost is an important issue in most projects within the national culture, and also managed to confirm the assertion that project managers from different countries conduct projects in different ways.

The PMPQ model application allowed Kozhakhmetova et al. (2019) to identify critical processes for projects in the green economy field and calculate the success rate of projects, implemented in Kazakhstan. The research used data from high-tech projects, implemented in Kazakhstan in the field of green energy. Implementation of the PMPQ model to identify critical areas of project management knowledge that affect project effectiveness and improve project management tools project, it was found that schedule management and project communication management, risk management, and quality management have the greatest impact on the effectiveness of projects in the field of green energy. Also, that green energy projects implemented in Kazakhstan have an average level of efficiency and an average score for the usage of project management processes. Critical processes for projects in the field of green energy are "activity definition", "assessment of the duration of activity", "risk management planning", "quality planning", and "communication planning" (Kozhakhmetova et al., 2019).

As for defense industry projects, there is active use of the processes like "determine budget", "estimate costs", and "develop project management plan". At the same time, the weakest places in the planning stage are "develop schedule" processes.

This fact suggests that defense projects adhere to the costs of project implementation. In contrast, unclear deadlines of the project's individual stages and processes, the lack of clearly defined relationships between operations within the project lead to non-compliance with the project's timing, which reduces its effectiveness. Today, project timing management is one of the very weak points in the system existing in the company under research.

To succeed, project managers must perform specific processes and a set of PM tools. A clear definition of responsibilities helps keep the project within budget and implemented according to the planned timelines, which will ultimately lead to effective monitoring of the implementation of processes and tasks in the projects and increase their quality level.

Critical processes such as "develop schedule", "define scope", and "plan human resource management" were identified when assessing areas of expertise that influence the success of the project.

Inadequate implementation of human resource planning, communications between project participants and departments are poorly established, there is no unified information system - these are processes that must be paid special attention to when initiating and planning the projects.

Using team-building activities can increase human resource planning effectiveness. This practice increases the group's cohesion and has several positive effects on the project's effectiveness. A more close-knit team can lead to a better outcome of the project, as team members can collaborate effectively to solve problems. The efforts of all project participants should be integrated. Tasks 
solved during the implementation of projects require a different level of knowledge and resources. When all project participants work together as a well-trained team under the project manager's integrative instruction, the likelihood of project success increases several times. These processes relate to high-quality areas; the use of these processes is extremely crucial and necessary for projects executed in the defense industry.

An assessment of the relationship between project management processes and the success rate of pro- jects of defense industry projects showed that the PQ index of projects is very low, which explains the low level of project success.

To eliminate all the problems and shortcomings of the currently existing project management processes in JSC "Kazakhstan Engineering", it is recommended to reengineer business processes. This event requires both organizational and technical changes, as well as very high financial costs. However, the results that will be obtained in the end will justify themselves in the implementation of projects.

\section{CONCLUSION}

Recently, project management has been developing very actively, both in the practice and research areas. The developed standards reflect the "best practices" in project management, considering critical success factors. Standards and research tell us that by implementing best practices and following critical success factors, there is an opportunity to improve project performance.

The research showed that the Kazakhstan's defense industry complex projects have a low level of efficiency and an average score for the use of project planning processes. The weaknesses of project management in this area were also identified. As the results show, project managers do not pay enough attention to such important areas of knowledge as human resource management, schedule development, and the definition of a list of operations.

The research expands knowledge in PM, revealing the importance of planning processes for the defense industry.

The limitations of this research are that it focuses only on Kazakhstan's defense industry projects. Future research should be expanded to include an analysis of the defense industries of various countries. Studying the success level of ongoing defense industry projects in various countries and comparing them with the results of projects in Kazakhstan will help to understand the direction of further development of the project management system in Kazakhstan.

\section{AUTHOR CONTRIBUTIONS}

Conceptualization: Alizhan Tulembayev, Aliya Adilova, Askhat Serikbekuly.

Data curation: Aliya Adilova, Dina Seidaliyeva, Yerlan Shildibekov.

Formal analysis: Alizhan Tulembayev, Aliya Adilova, Dina Seidaliyeva.

Investigation: Alizhan Tulembayev.

Methodology: Alizhan Tulembayev, Askhat Serikbekuly.

Project administration: Alizhan Tulembayev.

Resources: Alizhan Tulembayev, Askhat Serikbekuly, Yerlan Shildibekov.

Software: Askhat Serikbekuly, Alizhan Tulembayev.

Supervision: Yerlan Shildibekov, Askhat Serikbekuly.

Validation: Alizhan Tulembayev, Yerlan Shildibekov, Askhat Serikbekuly.

Visualization: Aliya Adilova, Askhat Serikbekuly, Dina Seidaliyeva.

Writing - original draft: Alizhan Tulembayev, Aliya Adilova, Yerlan Shildibekov.

Writing - review \& editing: Aliya Adilova, Dina Seidaliyeva. 


\section{ACKNOWLEDGMENT}

This study is the second part of grant AP05134488 that has been funded by the Ministry of Education and Science of the Republic of Kazakhstan.

\section{REFERENCES}

1. Baklanova, J. O.(2010). Otsenka effektivnosti upravleniya regionalnymi innovatsiyami [Assessment of the regional innovation management effectiveness]. UEKS, 22. (In Russian). Retrieved from https://cyberleninka.ru/article/n/ otsenka-effektivnosti-upravlenieregionalnymi-innovatsiyami

2. Cantwell, P. R., Sarkani, S., \& Mazzuchi, T. (2012). The effect of using a systems approach to project control within the U.S. defense industry. In Proceedings of the 2012 IEEE International Systems Conference SysCon 2012, Vancouver, BC, Canada (pp. 646650). https://doi.org/10.1109/SysCon.2012.6189454

3. Chang, A., Chih, Y.-Y., Chew, E., \& Pisarski, A. (2013). Reconceptualising mega project success in Australian Defence: Recognising the importance of value cocreation. International Journal of Project Management, 31(8), 11391153. https://doi.org/10.1016/j. ijproman.2012.12.005

4. Cronbach, L. J. (2004). My current thoughts on coefficient alpha and successor procedures. Educational and Psychological Measurement, 64, 391-418. https://doi. org/10.1177/0013164404266386

5. Daniel, R. H. (1961). Management data crisis. Harvard Business Review, 111-112.

6. Demir, K. (2017). Characteristics of Large-Scale Defense Projects and the Dominance of Software and Software Project Management. https://doi.org/10.1007/978-3319-54325-3 4

7. Dvir, D., Raz, T., \& Shenhar, A J. (2003). An empirical analysis of the relationship between project planning and project success. International Journal of Project Management, 21(2), 89-95.
https://doi.org/10.1016/S0263-

7863(02)00012-1

8. Frinsdorf, O., \& Zuo, J. (2014). Critical factors for project efficiency in a defence environment. International Journal of Project Management, 32(5), 803-814. https://doi.org/10.1016/j.ijproman.2013.10.008

9. Gadermann, A., Guhn, M., \& Zumbo, B. D. (2012). Estimating ordinal reliability for Likert - type and ordinal item response data: A conceptual, empirical, and practical guide. Practical Assessment, Research \& Evaluation, 17(3), 1-13. Retrieved from https://www.researchgate.net/ publication/236605201_Estimating_ordinal_reliability_for_Likerttype_and_ordinal_item_response_data_A_conceptual_empirical_and_practical_guide

10. Glenn, G. (2008). Enterprise Resource Planning 100 Success Secrets - 100 Most Asked Questions: The Missing ERP Software, Systems, Solutions, Applications and Implementations Guide: The Missing ERP Software, Systems, Solutions, Applications and Implementations Guide (150 p.). Retrieved from https://www.amazon.co.uk/Enterprise-Resource-Planning-SuccessSecrets/dp/0980497183

11. Joslin, R., \& Muller, R. (2015). Relationships between a project management methodology and project success in different project governance contexts. International Journal of Project Management, 33(6), 1377-1392. https://doi.org/33. 10.1016/j.ijproman.2015.03.005.

12. Junqueira, Michele Aparecida Dela Ricci, \& Passador, Cláudia Souza. (2019). The impact of the project management office on scientific research. Revista de Administração Pública, 53(6), 1179-1188. https://doi.org/10.1590/0034-

\section{$761220180125 x$}

13. Kozhakhmetova, A., Gabdullin, K., Kunanbayeva, D., Tazhiyeva, S., \& Kydayberganova, R. (2019). Green Energy Project's Efficiency: a Cross-Industry Evaluation. International Journal of Energy Economics and Policy, 9(5), 207215. https://doi.org/10.32479/ ijeep. 8137

14. Kozhakhmetova, A., Zhidebekkyzy, A., Turginbayeva, A., \&Akhmetova, Z. (2019). Modelling of project success factors: A crosscultural comparison. Economics and Sociology, 12(2), 219-234. https://doi.org/10.14254/2071789X.2019/12-2/13

15. Papke-Shields, K., Beise, C., \& Quan, J.. (2010). Do project managers practice what they preach, and does it matter to project success?. International Journal of Project Management, 28(7), 650-662. https://doi.org/10.1016/j. ijproman.2009.11.002

16. Paton, S., \& Andrew, B. (2019). The role of the Project Management Office (PMO) in product lifecycle management: A case study in the defence industry. International Journal of Production Economics, 208, 43-52. https://doi. org/10.1016/j.ijpe.2018.11.002

17. Pinto, J. K., \& Slevin, D. P. (1987). Critical Factors in Successful Project Implementation. IEEE Transactions on Engineering Management, EM-34, 22-27. Retrieved from https://www. researchgate.net/publication/260621619_Critical_Factors in_Successful_Project_Implementation

18. PMBOK. (2004). A Guide to the Project Management Body of Knowledge (4th ed.). Pennsylvania: Newtown Square.

19. Project Management Institute (PMI). (2017). A guide to the 
project management body of knowledge (PMBOK guide). Newtown Square:Project Management Institute.

20. Ress-Caldwell, K., \& Pinnington, A.H. (2013). National culture differences in project management: Comparing British and Arab project managers' perceptions of different planning areas. International Journal of Project Management, 31(2), 212-227. https://doi.org/10.1016/j.ijproman.2012.04.003

21. Rodríguez-Segura, E., OrtizMarcos, I., Romero, J. J., \& Tafur-Segura, J. (2016). Critical success factors in large projects in the aerospace and defense sectors. Journal of Business Research,
69(11), 5419-5425. https://doi. org/10.1016/j.jbusres.2016.04.148

22. Rubin, I. M., \& Seeling, W. (1967). Experience as a factor in the Selection and performance of Project Managers. IEEE Transactions Engineering, 14(3), 131-134. Retrieved from https://ieeexplore.ieee.org/ document/6448338

23. Tulembayev, A. N., Jumadilova, Sh G., Adilova, A. M., \& Seidaliyeva, D. (2019). Introducing project management system into enterprises of defense industry in Kazakhstan. Problems and Perspectives in Management, 17(2), 527-540. https://doi.org/10.21511/ ppm.17(2).2019.41

24. Zwikael, O., \& Globerson, S. (2006a).From Critical Suc- cess Factors to Critical Success Processes. International Journal of Production Research, 44(17), 3433-3449. https://doi. org/10.1080/00207540500536921

25. Zwikael, O., Dutt Pathak, R., Singh, G., \& Ahmed, S. (2014). The moderating effect of risk on the relationship between planning and success. International Journal of Project Management, 32(3), 435-441. https://doi.org/10.1016/j. ijproman.2013.07.002

26. Zwikael, O.,\& Globerson, S. (2006b). Benchmarking of project planning and success in selected industries. Benchmarking: An International Journal, 13, 688-700. https://doi. org/10.1108/14635770610709059 